\title{
Saudi EFL Instructors' and Students' Perspectives Towards Virtual Learning During COVID-19 Pandemic
}

\author{
Ahmed Alghamdi \\ English Language Institute, King Abdulaziz University \\ Jeddah 80200, Saudi Arabia \\ Tel: 966-12-695-2000 Ext 74560 E-mail: amoalghamdi@kau.edu.sa
}

Received: November 8, 2021 Accepted: December 4, 2021 Published: December 7, 2021

doi:10.5296/ijl.v13i6.19305

URL: https://doi.org/10.5296/ijl.v13i6.19305

\begin{abstract}
The Covid-19 pandemic and the sudden transition from face-to-face to virtual learning have given rise to various challenges and obstacles in teaching contexts all over the world. This paper explores the impact of this unexpected transition in the teaching and learning process based on English as a foreign language (EFL) teachers' and learners' experiences at a Saudi university. This research employed a mixed methods approach. Four male and female EFL teachers were involved in addition to thirty-six students from a preparatory year program. The key findings of the study revealed that there were three major challenges encountered in the use of virtual classroom applications during the pandemic, including crucially a lack of technology and Internet connection, having large numbers of students in a virtual learning classroom, and lack of student and teacher interaction when using virtual learning classes. Although Saudi EFL students and teachers viewed the virtual learning classes in a positive light during the pandemic period, they reported that in the post-pandemic period and over the long term, they would prefer traditional face-to-face teaching.
\end{abstract}

Keywords: Virtual learning classes, English as a foreign language, COVID-19, Internet, Technology, Pandemic

\section{Introduction}

\subsection{Background}

The entire world witnessed the disruption to schooling systems, higher education institutes included, due to the unexpected transition from face-to-face teaching to the virtual classroom (hereafter VC) because of the COVID-19 pandemic (Carrillo \& Flores, 2020). To maintain teaching and learning practices as usual, countries were forced to use various technology-based devices (Blackboard, Microsoft, etc.) (Day et al., 2021). The Kingdom of Saudi Arabia (KSA) 
was no exception. Many researchers in foreign language teaching have emphasised that teachers' and students' perspectives are particularly crucial when new applications are used (Wart et al., 2020). Dawson et al. (2019) for instance, stated the importance of seeking instructors' and students' perspectives to obtain pragmatic and valuable insights regarding their experiences and expectations. The rationale for involving both teachers and students as participants in this study was to obtain in-depth insights regarding their different experiences and perceptions of VCs. In the existing literature, researchers use various terms to describe the use of online teaching and learning. Most are discrete concepts with diverse implications, but are often applied interchangeably (e.g., virtual learning, virtual classes, distance learning, online teaching and learning, online education and remote teaching and learning) (Carrillo \& Flores, 2020). In this study, virtual learning (VL) and virtual classes (VC) are used interchangeably.

\subsection{Problem Statement}

At the beginning of the COVID-19 pandemic, the Saudi higher education sector was forced to implement various strategies due to the unexpected shift to virtual learning (hereafter VL). This gave rise to some challenges and limitations, but also to opportunities that needed to be studied. For instance, teachers required understanding of the use of online teaching, applying active learning online, as well as marking students' work. Delivering the subject content to the students required substantial efforts and solid infrastructure (Internet, computers/laptops). One issue that arose was the extent to which Saudi EFL instructors and students perceived VCs were appropriate in meeting their language teaching and learning needs during the COVID-19 pandemic. Thus, exploring teachers' and students' perspectives concerning their virtual teaching and learning experiences, specifically focusing on the challenges they faced, could help provide possible suggestions for successful implementation and recommendations for future studies.

\subsection{Significance of the Study}

The main purpose of this study is to investigate the role of VCs in students' English language learning during the ongoing COVID-19 pandemic. For VCs to be useful, it is necessary to investigate how both teachers and students perceive their implementation as a key factor in ensuring effective language teaching and learning. Thus, this study seeks to achieve the following objectives: (a) to investigate Saudi EFL teachers' and students' perspectives concerning the importance of VCs at a Saudi university under the COVID-19 pandemic restrictions; (b) to investigate teachers' and students' perceptions of the usefulness of VCs; (c) to identify potential challenges that participants encounter during the implementation of VL; (d) to provide suggestions for future studies that might enhance VCs in the Saudi EFL context.

\subsection{Research Questions}

The overall purpose of this study is to explore Saudi EFL teachers' and students' perspectives on the implementation of VCs at a Saudi university during the COVID-19 pandemic. This research seeks to answer the following overarching question: What are Saudi EFL instructors and students' perceptions of the use of virtual learning during the COVID-19 pandemic? The 
following sub-questions are used to guide the design of the study and answer the main question:

1. To what extent have virtual classes been important during the COVID-19 pandemic?

2. How beneficial are virtual classes for fostering students' English language learning?

3. What are the challenges and obstacles in the application of virtual learning?

\section{Literature Review}

In the Saudi Arabian context, due to the disruption of educational systems, included, colleges and universities, shifted to the unexpected transition from face-to-face teaching to the virtual learning application (Al-Nofaie, 2020). As a historical background, in the last two decades, VL has become an increasingly common aspect of educational systems, in terms of changing the constructs of education (Buzzetto-More, 2007), such that scholars predicted that it would cause a change in basic assumptions in education. Numerous studies have argued the validity and advantages of VL as a powerful means of delivering quality education and enhancing classroom-based instruction (Buzzetto-More, 2007). In this paper, recent literature related to VL will be used throughout to identify teachers' and students' perceptions with respect to the research questions, specifically the use of VL for English language teaching and learning.

According to Hamouda (2020), EFL is of global significance and is thus a major subject taught across the world. Seeking effective methods of teaching EFL continues to be a challenge faced in modern-day education (Hamouda, 2020). Moreover, as noted by Brown and Johnson-Shull (2000), throughout the 1990s the Internet and computing underwent immense technological developments, thus assisting VL and e-learning platforms in gaining widespread exposure within the field of education. Because the convenience and accessibility of VL, Cerny and Heines (2010) note that schools in all stages of education have made substantial assurances to obtain VL platforms in the hope of improving their students' learning and attainment.

\subsection{Empirical Studies}

Numerous studies have shown the importance of implementing VL in EFL contexts to improve learners' language competence. For example, Khalawi and Halabi (2020) investigated Saudi EFL teachers' and students' perceptions of VCs at a Saudi English Language Institute. They used a quantitative survey with a few open-ended questions to obtain a comprehensive understanding of the participants' views. The results of the study showed that most of the teachers and students held positive attitudes towards the use of VCs in EFL, but overall preferred face-to-face classrooms. Nonetheless, some participants acknowledged the enormous role VCs played in improving learners' autonomy.

In a more recent study, Alahmadi and Alraddadi (2020) investigated the effectiveness of VL in teaching second language (L2) students. The study participants comprised 90 Saudi female undergraduate students, all registered on an English language course provided in the foundation year programme at a Saudi English Language Centre, with English language being the core module. The participants' English language proficiency was beginner to low-intermediate level. The study used a quantitative research approach based on a 
questionnaire containing 19 statements that aimed to identify the impact VCs had on the L2 students, as well as determining whether the students had a positive outlook about learning through VCs. The outcomes of the research revealed that communication and interaction among the Saudi participants in the VCs was of a good standard. Furthermore, the results showed the participants held positive perceptions of the use of VCs in their module. The study concluded that employing VCs for language teaching and learning would be viewed favourably by students in the Saudi learning environment.

Another study conducted in the Saudi Arabian context by Al-Nofaie (2020) examined the perceptions of Saudi university students concerning the education they received via Blackboard due to the pandemic. The objective of the study was to determine the students' preferred methods of VL and gain a broader understanding of how students view such learning experiences in unprecedented conditions. The study sample consisted of 25 university students undertaking English language as their major at a Bachelor of Arts level. Based on analysis of the students' learning logs, the results showed that the participants favoured asynchronous learning over synchronous learning, with most stating that the former method provided greater flexibility. Moreover, it is important to note that a proportion of the Saudi students, although a minority, were not in favour of online education for language learners.

Likewise, a study undertaken in Thailand, where education was also unsettled and transferred to being online-based because of the disruption caused by the COVID-19 pandemic, assessed the response of language instructors. Todd (2020) surveyed the views of 52 English language instructors in a Thai university using a questionnaire split into two sections. The first section asked the instructors to rate the importance of 17 potential issues that might arise in two stages of the VL experience, the first being in the initial week of online teaching and the second stage being several weeks later. The second section asked the instructors to provide potential solutions to these problems, and to state the advantages and disadvantages they saw in online teaching. The outcomes of the study showed that the instructors viewed the potential problems they might face as serious, but identified solutions, one suggestion being that lessons could be divided into "a greater number of shorter units" (Todd, 2020).

Despite succeeding in finding solutions to some of the problems they might face, the instructors emphasised that they could face difficulties in stimulating online activities for their students and marking their assignments. In general, the instructors were able to point out some positive aspects of e-learning, although there were also negative implications.

In a more recent study, Mulyani et al. (2021) investigated students' perceptions and preferences on English instruction through e-learning implementation during the COVID-19 pandemic. A qualitative approach was employed, and data was collected from 3 different higher education institutes involving 106 English class students in Aceh, Indonesia. The data was analysed through the thematic and comparative analyses approach. Results showed that half of the study participants showed negative attitude towards the internet network, the limitation of learning material explanation and absorption, a high need of internet quotas, and the social media influences. On the other hand, 59.6\% of the participants showed positive attitude towards features associated with the students' interest, for instance, e-learning implementation, 
engagement and enthusiasm, the flexibility of time and place, and the advance of digital technology usage and adaptation. In addition, the students expressed that, WhatsApp, Opensimka, Google Classroom, and Google Meet have become the four most preferable e-learning platform. However, the study concluded that sufficient mentoring and extra supporting digital tools are still necessary for the students and the lecturers.

In a related study, Alwahoub, Azmi and Jomaa (2020) analysed the perceptions of e-learning held by primary school students and instructors in Riyadh, Saudi Arabia. The researchers adopted a quantitative research approach, distributing two web-based questionnaires with items measured on a five-point Likert scale. The outcomes showed both students and instructors had positive views of VL From the instructors' perspective, presenting classes virtually helped develop their technological abilities, enabling them to learn and consequently aiding their productivity in delivering online sessions well to their students. The students stated that the use of VL platforms enhanced their computer knowledge, which gave them the opportunity to perform more efficiently technologically. Overall, despite VL being in the first stages of development, the pupils, and teachers at this primary school in Riyadh showed positive perceptions of virtual learning.

Concerning the importance of this study, to the best of my knowledge, no research has yet been undertaken on language teachers' and students' experiences in dealing with VL in a Saudi university setting. The aim of this paper is thus to fill the gap in the literature by examining the following three major concerns: the importance of VCs in the Saudi university context, the extent to which VL has been useful in fostering students' language learning, and the perceived challenges and limitations of applying VL in English language teaching and learning.

\section{Methods}

This section sets out the research methods used in this study to explore instructors' and students' perspectives with respect to the use of VL in the Saudi EFL context. The study primarily focused on the perceived impact of the use of VL on the teaching process in terms of enhancing students' English language competence from the instructors' and students' perspectives.

\subsection{Research Design}

The study employed a mixed methods approach, consistent with Plano-Clark and Ivankova's (2015) view that this helps to address complex research purposes within the margins of a single study, resulting in the global popularisation of the approach for scientific research. Moreover, Tashakkori et al. (2003) stated that the mixed methods approach "is widely employed over mono method designs to obtain ... understanding because [it] enables the strengths of some methods to compensate for the limitations of other methods" (p. 530). The quantitative data were collected through a questionnaire and the qualitative data comprised transcripts of recorded interviews. 


\section{Macrothink}

International Journal of Linguistics

ISSN 1948-5425 2021, Vol. 13, No. 6

\subsection{Research Participants}

The study sample comprised Saudi EFL male and female instructors $(\mathrm{N}=4)$ and students $(\mathrm{N}$ = 36) at a Saudi university. The students who willingly agreed to participate in this research, recruited through a systematic sampling approach (Teddlie \& Yu, 2007, p. 90), represented various ages (see Figure 1) and levels of language proficiency based on the Common European Framework of Reference (CEFR), as shown in Figure 2. The students completed a questionnaire which includes an open-ended statement to examine their opinion regarding the use of VL in their classroom. Then, semi-structured interviews were conducted with four EFL teachers to gain in depth and broad information undertaken remotely over Zoom due to the COVID-19 pandemic.

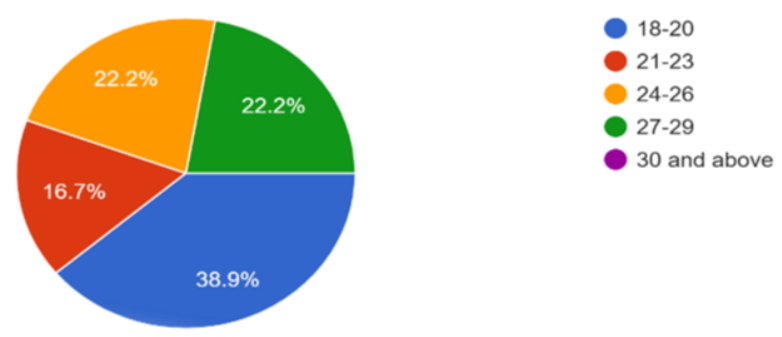

Figure 1. Distribution of student participants according to age

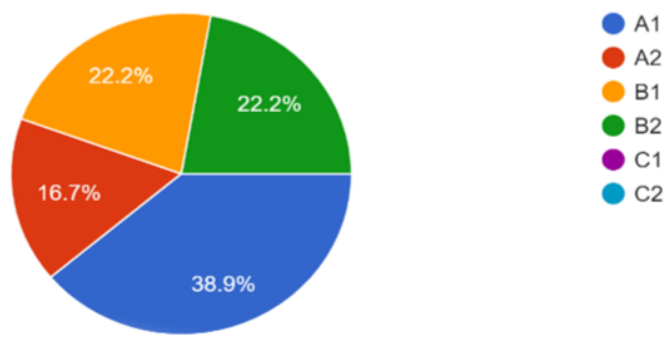

Figure 2. Student participants' English language level on the CEFR

Table 1. Instructors' demographic information $(\mathrm{N}=4)$

\begin{tabular}{cccc}
\hline Age & Educational level & Gender & $\mathrm{N}=4$ \\
\hline 35 & MA in TESOL & Male & 1 \\
41 & MA in Applied Linguistics & Male & 1 \\
43 & MA in Education & Female & 1 \\
38 & MA in TESOL & Male & 1 \\
\hline
\end{tabular}




\section{MInstitute ${ }^{\text {Mink }}$}

\subsection{Data Collection}

According to Rohrmann (2007: 2) questionnaires are the most-used method of data collection in social sciences, and almost all of them use rating scales as the primary response mode. The main research question in this study concerned the views of EFL instructors and students regarding the usefulness of VL during the COVID-19 pandemic. For this reason, a questionnaire was employed as the main research method to collect data from the students in the context and obtain insights into actual classroom practice, followed by semi-structured interviews with four EFL instructors. In addition, students were asked to add their comments as an answer to the open-ended question to help the researcher to triangulate the respondents' answers.

\subsection{Data Analysis}

In terms of the analysis of the qualitative data, I read the entire transcript of each teachers' interview initially to gain an overall idea of the content. On reviewing the transcripts for the second time, I applied marginal notes to code responses as positive and negative. These notes mainly applied to further clarifications by the participants made during the interview sessions. I then categorised and classified the data according to the research questions (importance and purpose of VL, effectiveness of VL, challenges facing the participants), i.e., applying a predetermined thematic coding (Dornyei, 2007). The findings obtained from the analysis of the students' questionnaire data including the open-ended question, (i.e., please state your opinion regarding your virtual learning experience). The data were then compared with the perceptions of EFL instructors in terms of both the teaching needs and students' learning needs to compare similarities and differences between the actual face-face courses and what needs to be done in the future regarding the application of VL in the Saudi language teaching context. To maintain anonymity, the participants are referred to by a number (T1, T2, T3, T4; S1, S2, S3, etc.).

\section{Results}

The reporting of the qualitative and quantitative findings is structured to provide a collective response to each research question.

\subsection{Students' Responses}

\subsubsection{Importance of Virtual Classes}

Regarding the first research question, the students were asked to indicate their opinions concerning the importance of VL during the COVID-19 pandemic on a Likert-type scale $(1=$ strongly disagree, $2=$ disagree, $3=$ agree, $4=$ strongly agree). 
6.a) "Virtual classrooms during the pandemic are important for English language learners" 36 responses

20

$20(55.6 \%)$

15

10

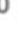

5

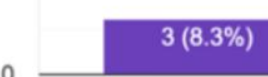

0

2

3

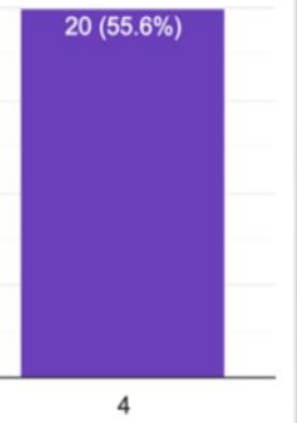

Figure 3. Importance of virtual learning from students' perspectives

As can be seen from Figure 3, most of the participants (28 out of 36) rated this item "strongly agree" and "agree", with only 8 out of 36 opting for "disagree" and "strongly disagree". Thus, the student participants viewed VCs as very important for English language learners during the pandemic. Furthermore, the students expressed their views regarding the importance of VL for English language learners. Although most of the students expressed satisfaction with VL, some did not, with one of the students stating that: "I don't like it because it is boring" (S6).

Moreover, students differ in terms of their preferred English language learning mode, with some favouring the face-to-face approach, while others are more active and motivated to participate in VCs.

One of the students stated: "I believe virtual learning is more beneficial and important for those who are interested students than for reactive learners" (S3).

\subsubsection{Usefulness of Virtual Classes}

The students were asked to rate the effectiveness of VL in the questionnaire by responding to four statements $(6 b, 6 c, 7 a$ and $7 b)$ aimed at exploring the usefulness of VL during the pandemic. 


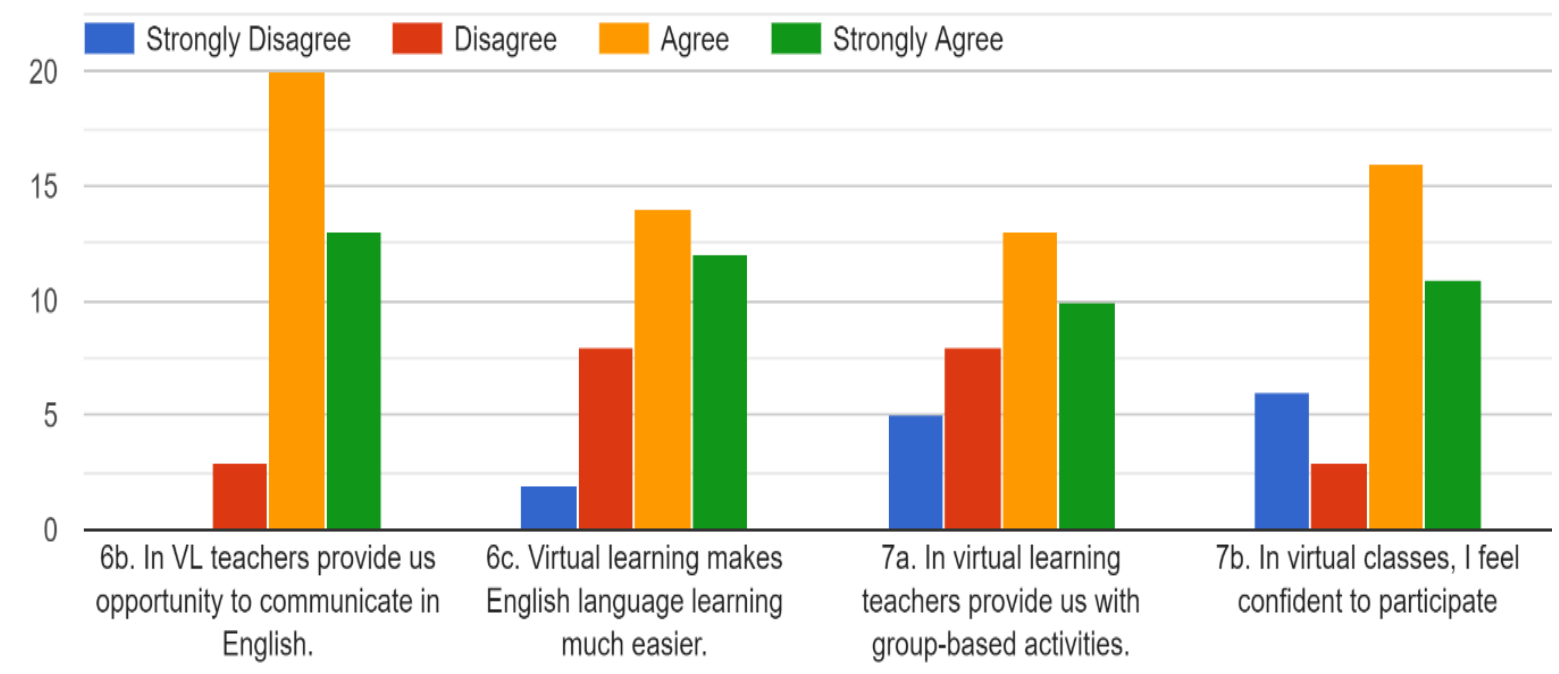

Figure 4. Perceived effectiveness of virtual learning during the COVID-19 pandemic

As can be seen from Figure 4, the students were asked about several aspects of the application of VL during the pandemic. Many of the students (33 out of 36) chose "strongly agree" and "agree" for teachers providing opportunities to communicate in English in VL, only 3 students selected "disagree" and none rated this statement "strongly disagree". Moreover, most of the students (26 out of 36) responded "strongly agree" and "agree" to VL making learning easier, with only 10 considering that the English language learning process was not easier in VCs. Responding to item 7a, 23 out of 36 students found that teachers in VCs provided them with group-based activities, but 13 chose the "strongly disagree" and "disagree" options. Concerning the fourth item, 7b, the majority (27 out of 36) of students chose the "strongly agree" and "agree" options, indicating that they felt confident participating in VCs. In addition, in response to the open-ended questions, the students expressed their views regarding the opportunities to communicate with teachers and share their thoughts during the VL. A group of students stated that: "It is a wonderful and comfortable experience, as well as the communication increases between us and the teachers.

We also recognized the effectiveness of communication in virtual classes. We feel more involved when we make conversation, ask questions and discuss assorted topics together." (S22, S12, S3, S6). However, some students (9 out of 36) were not in favour. As one put it:

"Actually, I am not amazingly comfortable with the virtual classroom application. I believe learning in a face-to-face class is easier and better for me." (S14) 


\section{Macrothink}

\subsubsection{Challenges and Obstacles to Virtual Learning}

The students were asked to rate the challenges and obstacles of VL in terms of whether they preferred VL over face-to-face classes, whether VCs helped them to improve their language ability or not and whether they felt confident participating in VCs.

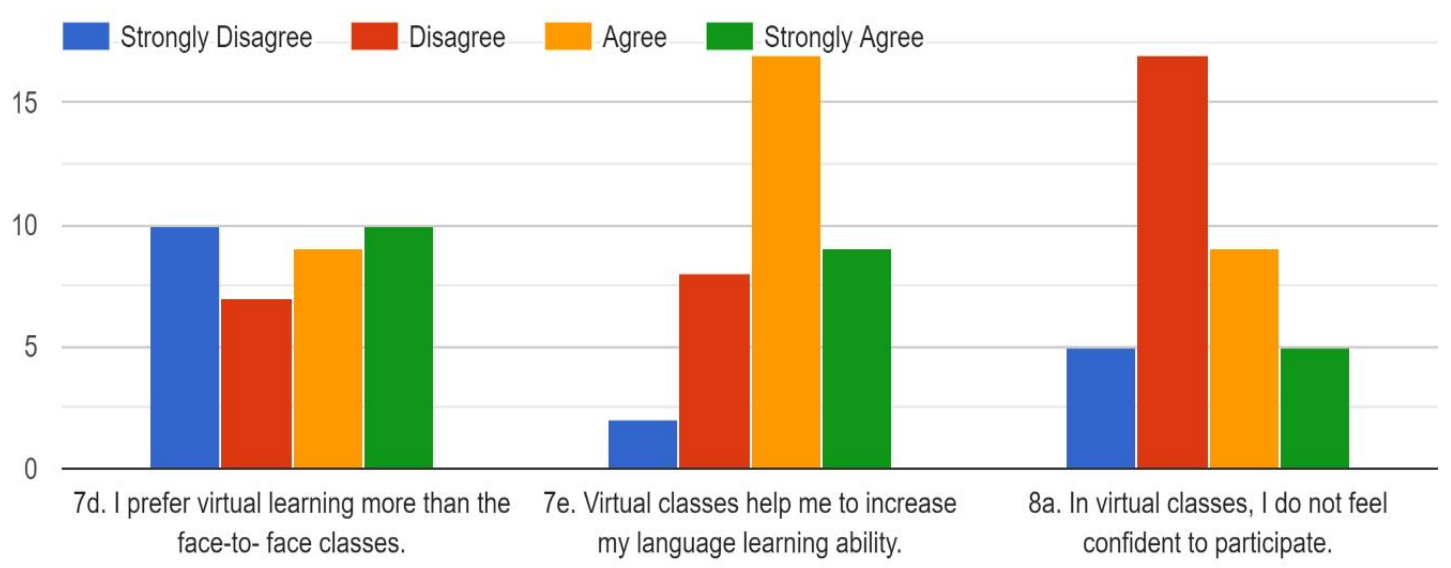

Figure 5. Challenges and obstacles to virtual learning

As can be seen from Figure 5, the responses to item 7d about preference for VL or face-to-face classes, 19 out of the 36 participants chose "strongly agree" and "agree", whereas 17 chose "strongly disagree" and "disagree". Regarding whether VL helped students to learn during the pandemic, 23 out of 36 students chose "strongly agree" and "agree", while only 13 opted for "strongly disagree" and "disagree". Item 8a asked the students to rate the statement "In virtual classes, I do not feel confident to participate". In response, 13 out of the 36 responded "strongly agree" and "agree", whereas 23 students responded, "strongly disagree" and "disagree". The participants also expressed their views regarding the above-mentioned issues. As one of the students stated:

"I believe in virtual classes; I have more opportunity and freedom to participate than in traditional classes with all my colleagues and teacher in the same place." (S21)

Moreover, another student stated:

"In terms of language learning, I enjoy the virtual learning experience since I can achieve it in my own comfort zone more than face-to-face classes." (S16) 


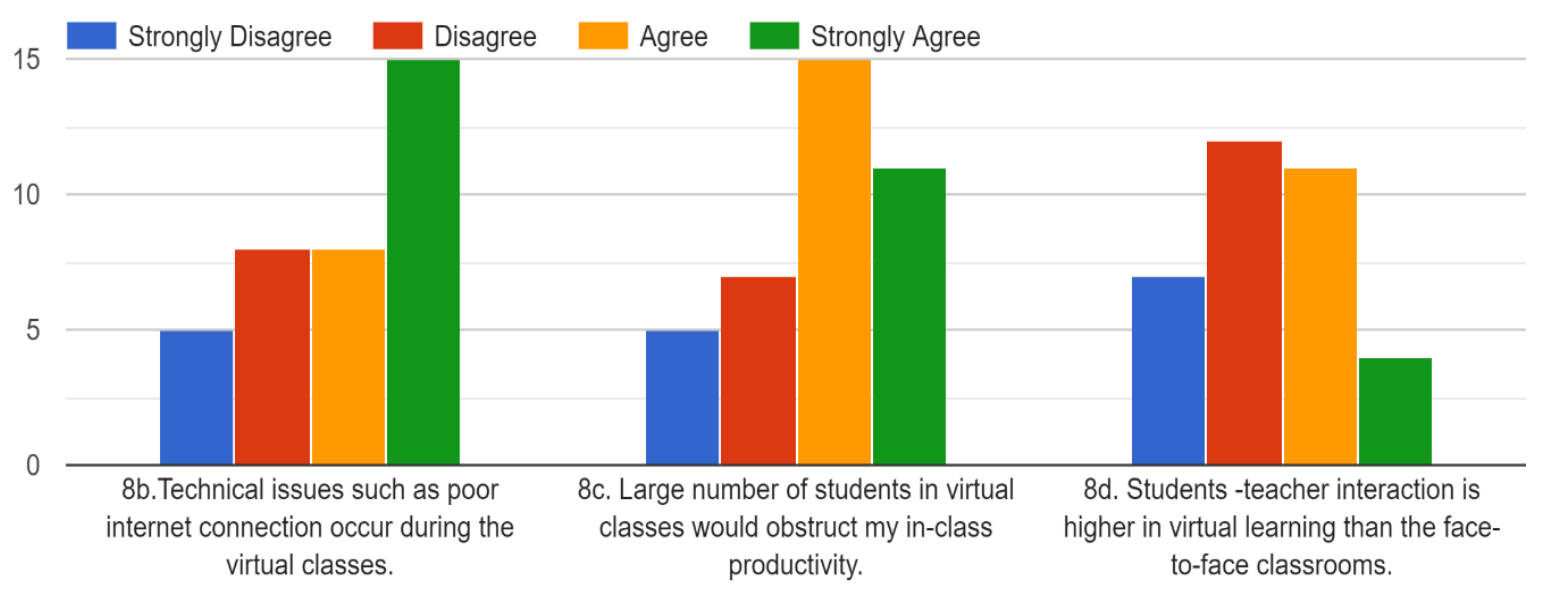

Figure 6. Technologically based challenges and obstacles

Concerning technological challenges to implementing VL, Figure 6 shows that 23 out of the 36 students responded, "strongly agree" and "agree" to technical issues such as a poor Internet connection occurring during VCs, while only 13 chose "strongly disagree" and "disagree". In terms of item 8c, the results show that 10 out of 36 students did not consider that having large numbers of students in VCs hindered their in-class productivity. However, most of the students (26 out of 36) agreed that large classes were one of the obstacles they encountered during VCs. Furthermore, in relation to student-teacher interaction during VL, 17 out of 36 "agreed" and "strongly agreed" that interaction was higher in VCs than in face-to-face classes. However, a slightly higher number (19) responded "strongly disagree" and "disagree". Although the responses were evenly distributed, the participants did highlight some advantages and disadvantages of learning in VCs, with a few students reporting:

"We believe that learning in a traditional class is more appropriate, but through virtual classes we can participate easily, and we can use the recorded classes any time, so in both classes students could achieve a lot of benefits." (S12, S31, S6)

\subsection{Teachers' Responses}

\subsubsection{The Importance of Virtual Classes}

In the semi-structured interviews with teachers, the first question was about the importance of VL during the pandemic. One of the teachers stated that:

"Virtual learning is a necessary tool especially during the current COVID-19 situation, because it is the only way that enables us to teach our students." (T3)

Another teacher also noted that: 
"During this period, I believe I had an opportunity to enhance my digital skills while I was teaching in virtual classes." (T1)

Another teacher stated that:

"To have the useful implementation, given the importance of VL in English language teaching and learning during the crisis curriculum writers and language programme leaders should work on examining how VL and face-to-face classes might be used together for the benefit of language learners" (T3).

\subsubsection{Usefulness of Virtual Learning}

The second interview question asked the teachers whether teaching in VCs allowed them to provide opportunities for students to communicate and share their thought, and the extent to which VL useful during the pandemic. One of the teachers stated:

"Virtual classes had more advantages with active students than passive students. What I have noticed during the virtual learning process is that students who used to be nervous or less productive in terms of classroom participation, I found them now more active compared to the traditional or physical classes." (T4)

Another teacher considered that:

"Despite some of the technical problems which affect the connection during the teaching sessions, I believe virtual classes are very effective in terms of providing teachers certain opportunities to share students' concerns, answering their questions to some extent." (T1)

Another interesting point raised by one of the teachers. She noted that:

"I would recommend that having some procedures, in terms of providing an online academic adviser to minimise the impact of any negative attitudes due to unexpected educational shift from face-to-face to a virtual learning which occurred during pandemic period." (T2)

\subsubsection{Challenges and Obstacles to Virtual Learning}

In several ways and repeatedly, the teachers were asked to describe the challenges they faced using VL during the COVID-19 pandemic. The teachers expressed numerous challenges that they faced, for instance reporting:

"We believe that virtual classes are helpful during such circumstances [i.e., the COVID-19 pandemic], but they cannot replace the face-to-face classroom. In virtual classes, the quality of the teacher's and students' interaction is extremely poor due to the absence of motivation. Also, students on the other side assume that someone else will answer and are less motivated to answer teachers' questions." (T1, T3, T4). 
Another teacher stated:

"There are more obstacles in virtual classrooms than in ordinary classes. Technical issues such as the Internet, microphone, students' inadequate skills in dealing with technology." (T4)

Another teacher made the critical point that:

"During virtual learning, the teacher's authority is reduced compared to normal face-to-face classes. The students need some sort of authority to manage their classroom behaviour." (T2)

The teachers were also asked to explain their teaching methods in VL. Most of the participants' views can be summarised in this statement:

"We ask the students to read the paragraph first and discuss the main ideas within themselves to ask possible questions. However, in current virtual classes, technological faults, such as poor Internet, contributed to some of the difficulties that students already faced during these sorts of classes." (T1, T2, T3, T4)

T3 also noted:

"No doubt there are more obstacles in virtual classrooms than in ordinary classes. For example, the Internet, microphones, less interaction with students and teachers, and most of the students are passive in terms of classroom participation." (T3).

\section{Discussion}

This section discusses the results presented in this paper. It synthesises the findings to identify key areas needing further improvement in the implementation of VL. The following sub-sections address the research questions in turn, discussing the findings in relation to the reviewed literature. The first sub-section discusses the participants' perceptions of the importance of studying English language using VL(RQ1). The second sub-section considers the effectiveness of VL from the students' and teachers' perspectives (RQ2). The third sub-section identifies and articulates the challenges and obstacles faced by the students and EFL teachers in implementing VL (RQ3). The discussion draws on the data obtained from the open-ended questions in the students' questionnaire and the teachers' semi-structured interviews to ensure the validity of the study findings also addresses the limitations of the study. The aim was to identify the extent to which VL are effective in improving English language learners' language learning ability.

\subsection{Importance of Virtual Learning}

As discussed in the review of the existing literature, exploring teachers' and students' perceptions and knowledge with respect to the application of VL should be the starting point for the implementation of such an approach (Van Wart et al., 2020). In this study, the findings revealed that most of the participants held positive attitudes regarding the importance of VL. This issue was discussed further during the semi-structured interviews with the teachers' and the participants' responses reflected the belief that the serious situation presented by the 
COVID-19 pandemic forced English teaching in the Saudi context to make the shift to using VL applications and do so successfully. The participants each offered their own personal experience regarding the implementation of VL in their classrooms. The findings of this study, confirming that using VL was particularly important for English language learners in the pandemic, are in line with prior research (e.g., Alwahoub et al., 2020; Todd, 2020) reporting on the importance of VL and especially during the COVID-19 crisis. However, the findings revealed that the students preferred traditional, face-to-face classes over VL for several reasons, for instance the poor student-teacher interaction in VL compared to traditional classes, in line with the research of Khalawi and Halabi (2020). Interestingly though, given the importance of VL in English language teaching and learning during the crisis, the participants suggested that curriculum writers and language programme leaders should work on examining how VL and face-to-face classes might be used together for the benefit of language learners.

\subsection{Usefulness of Virtual Learning}

In this study, the usefulness of VL in terms of empowering teachers to provide opportunities for their students to communicate and share their thoughts in English was discussed. Some of the teachers appreciated the opportunity offered by VL to enabling communicating and the sharing of views. In addition, in the semi-structured interviews, some of the teachers were very specific about how their VL improved the students' language learning, specifically for those who were known to be shy and participate less during face-to-face teaching classes. Indeed, one of the teachers argued that despite VL presenting some problems, it was noticeable that there were advantages for shy students. For example, as the findings of the interviews indicated, teachers noticed that students who used to be nervous or less productive in terms of classroom participation showed more motivation and productivity in the VL compared to the traditional classes. These findings are in line with the work of Alahmadi and Alraddadi (2020), who found communication and interaction among Saudi participants in VL to be of a good standard.

Moreover, the effectiveness of VCs was also discussed from the students' perspectives, which can be summarised in terms of comparing traditional, face-to-face classes with VL. In their open-ended responses in the questionnaire, the students found the application of VL to be a great and comfortable experience in terms of improving student-teacher communication and classroom interaction. The students also reported that they recognised the effectiveness of learning in VL feeling more involved in class conversations, asking questions, and participating in various topics. A small number reported that they do not feel confident in VL and preferred learning in traditional, face-to-face classes, considering that VCs presented more problems and challenges. This is consistent with Khalawi and Halabi's (2020) study, which also found that although most teachers and students had positive attitudes towards VCs in EFL, they preferred face-to-face classes overall.

\subsection{Challenges and Obstacles to Virtual Learning}

The analysis of the EFL teachers' and students' perceptions revealed three primary challenges faced in using VCs during the COVID-19 pandemic. The first challenge was lack of technology and Internet connection issues. The teachers and students pointed out that technical issues, such as a poor Internet connection and issues with microphones were the 
main challenges in accessing VCs. The second challenge was having large numbers of students in VCs. The participants believed that teaching more students than expected had a major impact on the language learning and teaching process during the pandemic and most of the students reported that large classes was one of the obstacles they had encountered during VCs. In addition, the teachers considered that having large numbers of students in the VL environment reduced their authority in terms of managing the students' attitudes in class. Specifically, the teachers argued that in the absence of physical interaction, the students needed some sort of authority to manage and control virtual classroom behaviour. The quality and manner of student-teacher interaction in VL was the third challenge reported by the participants. When the teachers were asked to provide further explanation, they recounted that although VCs were effective in the specific circumstances of the COVID-19 pandemic, they could not replace the face-to-face classroom. They noted that in VCs the quality of interaction was very poor due to the lack of students' motivation to participate and get involved in the given classroom activity. It seemed that the students assumed someone else would answer the teacher's questions as they were not as immediately engaged as when attending the actual classroom. The teachers also argued that overloaded teaching hours made the student-teacher interaction process difficult and restricted the time available for communicative activities.

Interestingly, some of the teachers agreed that despite there being some technical problems in applying VCs, there were certain advantages for active students, in contrast to passive learners. Nonetheless, the participants reported that it was also clear during the pandemic that students who tended to be nervous or less productive in classroom participation showed greater motivation and productivity. The possible explanation for this could be that shy students feel more confident and relaxed engaging in VCs than in face-to-face classes. This finding confirms the results reported by Todd (2020), who found that instructors were able to point to some positive aspects of virtual classes, despite negative aspects also being present. In general, the findings of this study indicated that having positive attitudes towards VCs alone was not sufficient to improve the students' English language learning ability. However, a collaborative and integrated approach to teaching and learning, whether in virtual or traditional classes, is crucial for successful English language learning.

\section{Conclusion}

This study has drawn on teachers' and students' perspectives to determine the effectiveness of the application of virtual learning in terms of fulfilling the students' English language learning needs. The study discussed three major challenges in implementing virtual learning, namely lack of an Internet connection, having large numbers of students in the virtual classroom, and lack of student and teacher interaction. Nevertheless, the results also indicated that the participants viewed virtual classes as important, especially during the COVID-19 pandemic, enabling educational institutes to continue English language teaching and learning. Also, the findings showed that most of the participants, particularly the language learners, recognised the role of virtual learning in the EFL context in terms of the room it provided to participate and share their views. In addition, regarding preferences for teaching methods, the students believed that learning in a traditional class was more appropriate, but that virtual classes enabled them to participate freely and easily, and the students appreciated that they 
could access the recorded classes at any time. Most of the participants believed that large classes were an obstacle to virtual learning and the teachers considered that this reduced their authority and ability to manage students' behaviour, as well as hindering student-teacher interaction. In general, the results obtained from the analysis of both qualitative and quantitative data can be used as a framework for designing and planning virtual learning classes in similar contexts.

\subsection{Implications of the Study}

Based on the findings of this study, it is noticeable that the English language teaching and learning context in Saudi Arabia needs certain adjustments to make better use of VL applications as evidenced by the COVID-19 pandemic. The challenges and obstacles preventing the effective use of virtual learning in the Saudi university context must be resolved to maximise its use. In particular, the size of classes needs to be reduced and the technical issues, especially poor Internet connection, need to be resolved. In addition, in-service training should be provided to teachers, because some of the challenges inherent in the virtual learning process arise from the fact that teachers are not sufficiently familiar with dealing with technical issues. Therefore, professional training focusing on the use of the virtual learning environment should be designed and implemented for language teachers. Saudi researchers also need to conduct further studies to explore the needs and expectations of EFL learners in the Saudi context.

\subsection{Final Remarks}

This research investigated EFL teachers' and students' perspectives concerning the effectiveness of implementing virtual classes during the COVID-19 period. The paper has presented various aspects, namely the importance and effectiveness of VCs, and the challenges and obstacles they present. The purpose of this study was to improve the application of virtual classes for the benefit of English language learners. The overall conclusion is that VL requires considerable development to maximise the benefits. Initially, the three major challenges identified need to be addressed, i.e., technical issues and internet connectivity, the size of classes, and poor student and teacher interaction. The findings of the study also showed that the students lacked the required motivation to engage in virtual classes to develop their English language competence. The researcher also noticed that there are some limitations, which should be examined in future studies. For instance, the quantitative results could be enhanced by adding one more tool such as "classroom observation" to observe the virtual learning classes in terms of students' and teachers' virtual interaction. as well as some of the challenges that teachers face during the application of VL. The current study examined the usefulness of virtual learning application using only the participants' perceptions. However, far more findings would have been collected if the study were applied to measure the virtual learning outcomes using a control and experiment groups. Overall, more research needs to be conducted to identify the best use of VCs in collaboration with EFL teachers, language colleges and program developers. 


\section{References}

Alahmadi, N. S., \& Alraddadi, B. M. (2020). The Impact of Virtual Classes on Second Language Interaction in the Saudi EFL Context: A Case Study of Saudi Undergraduate Students. Arab World English Journal, 11(3), 56-72.

Al-Nofaie, H. (2020). Saudi University Students' Perceptions towards Virtual Education During Covid-19 Pandemic: A Case Study of Language Learning via Blackboard. Arab World English Journal, 11(3), 4-20.

Alwahoub, H. M., Azmi, M., \& Jomaa, N. (2020). Teachers' \& Students' Perceptions of E-Learning Integration in the Primary Schools of Saudi Arabia. International Journal of Advanced Research in Education and Society, 2(1), 116-126.

Bigne, E., Badenes, A., Ruiz, C., \& Andreu, L. (2018). Virtual classroom: teacher skills to promote student engagement. Journal of Management and Business Education, 1(2), 87-105.

Brown, G., \& Johnson-Shull, L. (2000, May/June). Teaching Online: Now We're Talking. The Technology Source, 46-60.

Carrillo, C., \& Flores, M. A. (2020). COVID-19 and teacher education: a literature review of online teaching and learning practices. European Journal of Teacher Education, 43(4), 466-487. https://doi.org/10.1080/02619768.2020.1821184

Cerny, M. C., \& Heines, J. M. (2010). Evaluating Distance Education Across Twelve Time Zones. Technological Horizons in Educational Journal, 28(7).

Cohen, L., Manion, L., \& Morrison, K. (2000). Research Methods in Education. London: Routledge Falmer.

Cohen, L., Manion, L., \& Morrison, K. (2007). Research methods in education. New York: Routledge.

Creswell, J. W., \& Plano Clark, V. L. (2018). Designing and conducting mixed methods research.

Creswell, J. W. (2014). Qualitative Inquiry \& Research Design: Choosing among Five Approaches (4th ed.). Thousand Oaks, CA: SAGE.

Dawson, P., Henderson, M., Mahoney, P., Phillips, Boud, D., \& Molloy, E. (2019). What makes for effective feedback: Staff and student perspectives. Assessment \& Evaluation in Higher Education, 44(1), 25-36.

Day, T., Catherine, C., Chung, C. K., Doolittle, W., Jacqueline, \& McDaniel, P. N. (2021). The Immediate Impact of COVID-19 on Postsecondary Teaching and Learning. The Professional Geographer, 73(1), 1-13. https://doi.org/10.1080/00330124.2020.1823864

Dornyei, Z. (2007). Research methods in applied linguistics. Oxford: Oxford University Press. 


\section{Al Macrothink}

International Journal of Linguistics

ISSN 1948-5425

2021, Vol. 13, No. 6

Gerring, J. (2010). Social Science Methodology: A Criterial Framework. Cambridge University Press.

Hamouda, A. (2020). The effect of virtual classes on Saudi EFL students' speaking skills. International Journal of Linguistics, Literature and Translation, 3(4), 174-204.

Khalawi, A., \& Halabi, M. (2020). An Inquiry into Saudi EFL Teachers and Students' Perceptions of EFL Virtual Classes and Its Relation to Learner Autonomy. International Journal of English Language Education, 8(2).

Kozma, R. B. (2001). Counterpoint theory of 'learning with media'. In R. E. Clark (Ed.), Learning from media: Arguments, analysis, and evidence (pp. 137-178). Greenwich, CT: Information Age Publishing Inc.

Long, M. H. (2005). Second language needs analysis. Cambridge: Cambridge University Press.

McDonough, J., \& McDonough, S. (1997). Research Methods for English language teachers. London, Arnold.

Means, B., Bakia, M., \& Murphy, R. (2014). Learning Online: What Research Tells Us About Whether, When and How. Routledge: Taylor \& Francis.

Mulyani, F., Suryani, Suri, M., \& Halimatussakdiah. (2021). University students' perceptions through e-learning implementation during COVID-19 Pandemic: Positive or negative features dominate?. Studies in English Language and Education, 8(1), 197-211.

Nicole A., \& Buzzetto-More, N. A. (2007). Principles of Effective Online Teaching. Informing Science Press.

Nicole A., \& Buzzetto-More, N. A. (2010). The E-portfolio Paradigm: Informing, Educating, Assessing, and Managing with E-portfolios. Informing Science Press.

Oppenheim, A. N. (2000). Questionnaire design, interviewing and attitude measurement. London: Continuum.

Plano Clark, V. L., \& Ivankova, N. V. (2015). Mixed Methods Research: A Guide to the Field.

Pring, R. (2000). Philosophy of education research. London: Continuum.

Richards, J. (2001). Curriculum Development in Language Teaching. Cambridge: Cambridge University Press.

Richards, K. (2003). Qualitative inquiry in TESOL. Basingstoke: Palgrave Macmillan.

Tashakkori, A., Teddlie, C., \& Teddlie, C. B. (2003). Handbook of Mixed Methods in Social \& Behavioral Research.

Todd, W. (2020). Teachers' Perceptions of the Shift from the Classroom to Online Teaching Richard. International Journal of TESOL Studies, 2(2), 4-16. 


\section{Macrothink}

International Journal of Linguistics

ISSN 1948-5425 2021, Vol. 13, No. 6

Van Wart, M., Ni, A., Ready, D., Shayo, C., \& Court, J. (2020). Factors leading to online learner satisfaction. Business Educational Innovation Journal, 12(1), 15-24.

Walliman, N. (2005). Your Research Project: A step by step guide for the first- time researcher (2nd ed.). SAGE Publications Ltd.

\section{Copyrights}

Copyright for this article is retained by the author(s), with first publication rights granted to the journal.

This is an open-access article distributed under the terms and conditions of the Creative Commons Attribution license (http://creativecommons.org/licenses/by/4.0/) 